\title{
IMPLEMENTASI PEMBELAJARAN BAHASA INGGRIS BERBASIS MOBILE-ASSISTED LANGUAGE LEARNING (MALL) UNTUK GENERASI NEO-MILENIAL
}

\author{
Suci Ramadhanti, Salma Putri Nursehan, Rafi Abdullah \\ suci.ramadhanty81@gmail.com \\ Mahasiswa Fakultas Keguruan dan Ilmu Pendidikan Universitas Ibn Khaldun
}

\begin{abstract}
ABSTRAK
Bahan ajar yang familiar merupakan sesuatu yang penting karena dapat meningkatkan kreativitas siswa. Pada era seperti ini, bahan ajar yang familiar dapat ditemukan dari lingkungan sekitar siswa. Seperti sosial media yang sangat familiar bagi siswa. Namun tidak semua sosial media memiliki fitur yang sesuai untuk dijadikan bahan ajar. Melalui aplikasi Line yang menyediakan fitur Relay, siswa akan memiliki kesempatan untuk menemukan ideide baru ketika membuat sebuah penulisan karya tulis. Sehingga hasil yang mereka dapatkan menjadi lebih kreatif dan mereka mudah untuk memahami ide-ide yang mereka telah pikirkan sebelumnya.
\end{abstract}

\section{Kata Kunci: Fitur Relay, Kreativitas Menulis, Optimalisasi Pembelajaran.}

\section{PENDAHULUAN}

Neo-milenial atau yang lebih dikenal juga sebagai 'Generation Z' adalah sebuah generasi atau kelompok orang yang lahir dalam kurun waktu tahun 1995-2010, generasi ini merupakan pengganti atau penerus dari generasi milenial atau generation y. Generasi ini dikenal sebagai generasi yang terbiasa hidup dengan teknologi dan media sosial sejak kecil (digital native) (Mohr \& Mohr, 2017).

Dalam bidang pendidikan, khususnya pendidikan bahasa Inggris merupakan sebuah tantangan tersendiri bagi guru dalam mengajarkan bahasa Inggris pada generasi neo-milenial. Pasalnya sebagai generasi yang terbiasa dengan teknologi dan media sosial, neo-milenial lebih menyukai pembelajaran yang berbasis teknologi dan media sosial sebagai media belajar. Namun, pembelajaran yang sudah ada sekarang ini khususnya di Indonesia dinilai masih belum dapat mengakomodasi sifat dasar generasi neo-milenial yang terbiasa hidup dengan teknologi dan media sosial sejak kecil (digital native). Guru masih menjadi fokus dalam proses pembelajaran bagi siswa di kelas, dan guru masih memberikan instruksi yang sama pada semua siswa, padahal siswa memiliki kemamapuan dan kebutuhan belajar yang berbeda-beda (Takeda, 2016).

Untuk dapat mengakomodasi kemampuan dan kebutuhan dengan sifat alami generasi neo-milenial, dibutuhkan sebuah inovasi dalam pembelajaran seperti menjadikan salah satu teknologi yang paling banyak digunakan dan dimiliki saat ini yaitu perangkat seluler atau smartphone sebagai media belajar bagi siswa baik di dalam maupun di luar kelas. Hal ini tidak 
lain dan tidak bukan karena generasi neomilenilal sebagai generasi yang lahir dan besar dalam dunia teknologi selalu membawa perangkat seluler atau smartphone ke sekolah, ke dalam kelas dan kemanapun mereka pergi (Pim, 2013). Bahkan berdasarkan survei yang dilakukan oleh Kominfo pada tahun 2014 yang bekerja sama dengan UNICEF, "sebanyak 30 juta anak muda di Indonesia adalah pengguna internet dan media digital sebagai saluran utama komunikasi yang mereka pakai dalam kehidupan seharihari” (kominfo.go.id).

Dengan mengadaptasi kebiasaan siswa yang selalu mengakses telepon seluler atau smartphone, baiknya pembelajaran bahasa Inggris dilakukan dengan menggunakan pendekatan MALL (Mobile Asisted Language Learning) yaitu sebuah pendekatan dengan menggunakan perangkat seluler untuk kegiatan belajar mengajar (Lindaman \& Nolan, 2015), sehingga tidak hanya dapat mengakomodasi pembelajaran pada generasi neo-milenial tetapi juga dapat memberikan pembelajaran kapan saja dan dimana saja sesuai dengan sifat asli generasi neo-milenial.

Banyak sekolah di berbagai negara yang sudah mulai menerapkan pendekatan ini di kelas seperti salah satu sekolah di Kairo, Mesir yang menggunakan aplikasi Facebook untuk berdiskusi dan melatih keterampilan bahasa siswanya seperti writing, reading, grammar, dan pronunciation (Stanley, 2013). Kemudian salah satu sekolah di Turki menggunakan MALL dengan mengadaptasi pendekatan "bring your own device" dimana siswa diberikan sebuah projek yang harus diselesaikan sendiri atau bersama kelompok dengan menggunakan fitur perangkat seluler seperti kamera, perekam suara, dan aplikasi pada telepon seluler seperti Voki (Stanley, 2013).

Untuk negara Indonesia sendiri penggunaan dan pengenalan pembelajaran dengan menggunakan pendekatan MALL masih belum merata dan sangat sedikit, khususnya di kalangan perguruan tinggi dan sekolah (Yudhiantara \& Saehu, 2017). Padahal banyak negara baik negara maju maupun berkembang yang sudah membuktikan keefektifan pendekatan ini yang lebih mudah dalam penggunannya bagi siswa khususnya generasi neomilenial dan mendukung banyak apllikasi yang dapat meningkatkan pengalaman belajar siswa dalam keterampilan bahasa Inggris di dunia nyata. Dengan tujuan melakukan perbaikan pada sistem pembelajaran bahasa Inggris di sekolah dengan menggunakan pendekatan MALL dan memperkenalkan media-media pada MALL yang dapat diterapkan di sekolah sebagai media untuk belajar dan menggembangkan kemampuan siswa dalam pembelajaran bahasa Inggris, diharapkan gagasan ini dapat menjadi salah satu solusi dan inovasi dalam pembelajaran dan pengajaran bahasa Inggris bagi generasi neo-milenial, agar melalui gagasan ini siswa, guru dan sekolah dapat memahami penggunaan MALL pada pembelajaran bahasa Inggris dan dapat memberikan gagasan baru bagi guru dalam pembelajaran bahasa Inggris di abad 21, karena pada hakikatnya kunci kesuksesan sebuah bangsa terletak pada pendidikannya, jika pendidikan yang diterapkannya bagus dan dapat bersaing dengan negara lain maka negara tersebut menjadi negara yang berhasil. 


\section{GAGASAN}

\section{Kondisi Terkini}

Ada banyak sekali masalah dalam pembelajaran bahasa Inggris khususnya yang terjadi di sekolah sejak bahasa Inggris menjadi bahasa asing bagi negara Indonesia dan dimasukan pembelajarannya kedalam muatan lokal di sekolah. Berbagai masalah ini datang baik dari instansi, guru dan siswa sendiri. Permasalahan ini meliputi; pertama pembelajaran dalam bahasa Inggris yang dirasa kurang memberikan praktik bagi siswa, kedua siswa kurang memiliki motivasi dalam belajar bahasa Inggris karena pembelajaran bahasa Inggris selalu disajikan dengan konten dan media yang kurang menarik bagi siswa terutama generasi neo-milenial (Dehghan, Rezvani, \& Fazeli, 2018), dan ketiga penerapan pembelajaran yang masih menggunakan teacher-centered (pembelajaran yang berpusat pada guru) menyebabkan kurangnya komunikasi antar siswa dengan guru dalam proses pembelajaran bahasa Inggris (Boholano, 2017).

Atas dasar banyaknya permasalahan yang dihadapi pada pembelajaran bahasa Inggris terutama dengan menggunakan cara tradisional akhirnya pada tahun 1997
Levy memperkenal pendekatan berbasis teknologi dengan menggunakan Computer Asisted Language Learning (CALL) sebagai inovasi pada pembelajaran bahasa Inggris di kelas. Namun seiring berjalannya waktu, pendekatan ini menemui masalah dalam penerapannya di dalam kelas, tidak semua siswa memiliki komputer atau laptop baik di sekolah maupun di rumah yang akhirnya menyebabkan siswa kurang bisa memanfaatkan teknologi yang ada pada komputer untuk meningkatkan kemampuan bahasa Inggris mereka (Stanley, 2013).

Kemudian diperkenalkanlah pendekatan dengan menggunakan web 2.0 sebagai media dalam pembelajaran bahasa Inggris, pendekatan ini adalah pengembangan dari pendekatan sebelumnya, dimana web 2.0 sebagai basis web blog pada internet menyajikan beberapa alat atau media yang dapat digunakan siswa dalam pembelajaran bahasa Inggris baik di dalam ataupun di luar kelas, baik menggunakan komputer ataupun telepon seluler/smartphone. Beberapa alat yang disediakan web 2.0 dalam pembelajaran bahasa Inggris adalah seperti:

\begin{tabular}{|c|c|}
\hline Media Web 2.0 & Konteks Pembelajaran \\
\hline Blog & Reading \\
\hline Wikis & Reading, writing, vocabulary \\
\hline Bubble and Pebble & Reading \\
\hline Voki & Writing, speaking \\
\hline
\end{tabular}

Tabel 2.1.1 Media web 2.0 dalam pembelajaran bahasa Inggris

Sumber: Motteram, 2013.

Namun lagi-lagi pendekatan ini menemui masalah yaitu dimana fitur-fitur yang terdapat pada web tidak sama ketika dibuka dengan menggunakan komputer dan ketika dibuka dengan menggunakan telepon seluler atau smartphone. Ketika dibuka dengan telepon seluler atau smartphone beberapa fitur hilang, pemuatan konten yang berat dan aksesnya yang hanya menggunakan internet menjadi 
masalah dalam penerapan pendekatan ini. Untuk itu dibutuhkan pendekatan yang lebih efektif dan efisien dalam penggunaan teknologi pada pembelajaran bahasa Inggris di kelas.

\section{Solusi yang Pernah Ditawarkan}

a. CALL

Berdasarkan Levy

pendekatan CALL sendiri adalah pendekatan yang berbasis komputer dalam penggunaannya pada proses belajar dan mengajar (Yaman \& Ekmekçi, 2016). Contoh pembelajaran dengan menggunakan pendekatan ini adalah dengan menggunakan media video conferencing, power point dan windows movie maker (Motteram, 2013).

b. Web 2.0

Web 2.0 adalah basis web blog pada internet yang menyajikan beberapa alat atau media yang dapat digunakan siswa dalam pembelajaran bahasa Inggris baik di dalam ataupun di luar kelas, baik menggunakan komputer ataupun telepon seluler/smartphone (Stanley, 2013). Contoh pembelajaran dengan menggunakan pendekatan ini adalah dengan menggunakan blog, bubble and pebble, dan wikis (Motteram, 2013).

\section{Gagasan yang Diajukan}

Taj, Sulan, Sipra \& Ahmad (2016) mengatakan bahwa perangkat seluler merupakan miniatur dari komputer dan laptop dengan beberapa kelebihan dibandingkan dengan komputer dan laptop. Selain bentuk fisiknya yang kecil dan ringan sehingga memudahkan penggunanya dalam kegiatan sehari-hari, telepon seluler atau smartphone juga mendukung banyak aplikasi termasuk aplikasi untuk meningkatkan pembelajaran bahasa Inggris baik yang gratis maupun berbayar, baik menggunakan internet (online) ataupun tidak menggunakan internet (offline) (Miangah \& Nezarat, 2012). Atas dasar kepopuleran, keefektifan, keefisienan, dan manfaat dari telepon seluler, banyak ahli mengatakan dan sepakat bahwa pendekatan Mobile Asisted Language Learning (MALL) yaitu sebuah pendekatan dengan menggunakan perangkat seluler untuk kegiatan belajar mengajar (Lindaman \& Nolan, 2015) sangat efektif untuk digunakan dalam mengembangkan dan megajarkan pembelajaran bahasa Inggris pada generasi neo-milenial. Tidak seperti pendekatan CALL dan Web 2.0, pendekatan MALL dapat mengembangkan kemampuan siswa khususnya generasi neo-milenial pada pembelajaran abad 21 seperti kreativitas, komunikasi, pemikiran kritis dan kolaborasi (Takeda, 2016). Pembelajaran dengan menggunakan pendekatan ini juga dapat menciptakan lingkungan belajar yang nyata pada siswa dan sangat sesuai dengan sifat alami generasi neo-milenial yang sangat terbiasa dengan penggunaan teknologi dan media sosial sehingga pembelajaran dapat dilakukan dimana saja dan kapan saja (Boholano, 2017).

Media-media pada perangkat seluler atau smartphone yang dapat digunakan dalam pembelajaran bahasa Inggris:

a. Google Text-to Speach

Google Text-to Speech adalah sebuah aplikasi pembaca layar (screen reader) untuk sistem andorid atau perangkat seluler (chrome.google.com). Cara kerja aplikasi ini yaitu layar akan membaca apa yang dituturkan oleh 
penutur dan menterjemahkannya

kedalam bentuk teks.
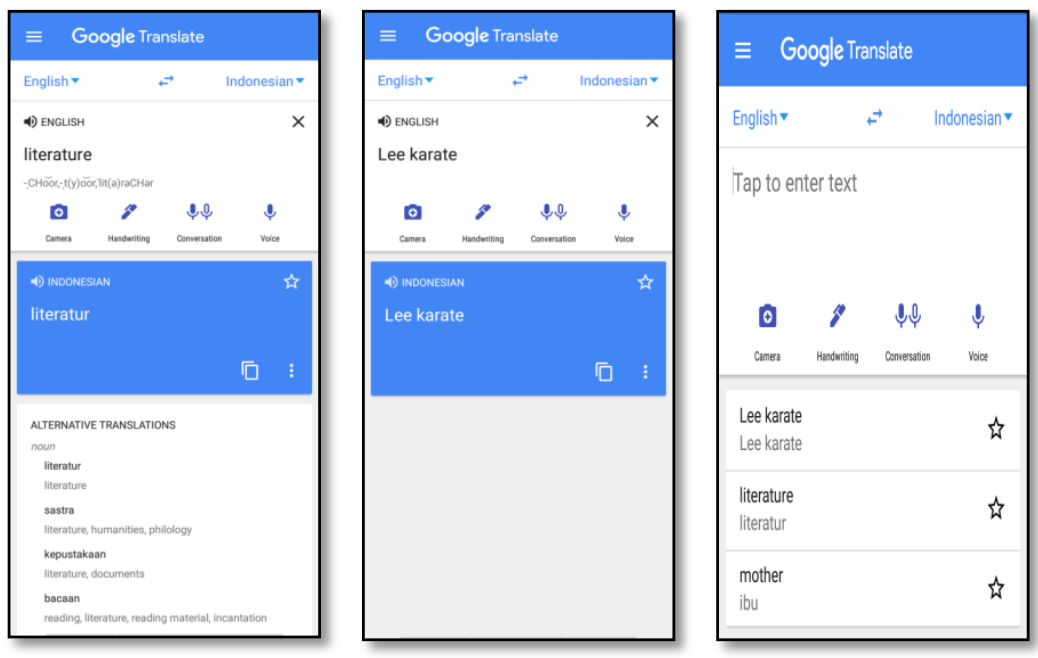

1.1.1 Tangkapan layar (screenshot) Google Translate

b. Edmodo

Edmodo adalah jaringan pembelajaran global yang membantu menghubungkan peserta didik dengan guru dan orang-orang atau sumber daya yang dibutuhkan untuk memenuhi kebutuhan belajar mereka (edmodo.com).
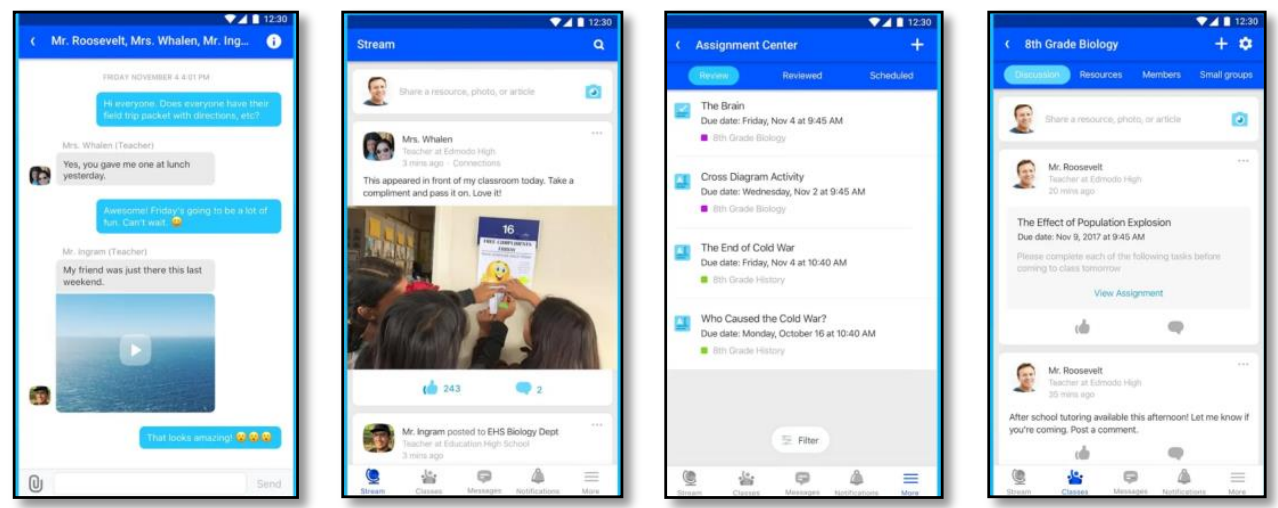

1.1.2 Tangkapan layar (screenshot) Edmodo

Sumber: edmodo.com

c. Google Classroom

Google classroom adalah salah satu aplikasi gratis yang dapat digunakan baik oleh guru maupun siswa untuk kegiatan belajar (Azhar \& Iqbal, 2018). Aplikasi ini betujuan untuk mempermudah proses berbagi materi antara guru dan siswa. 

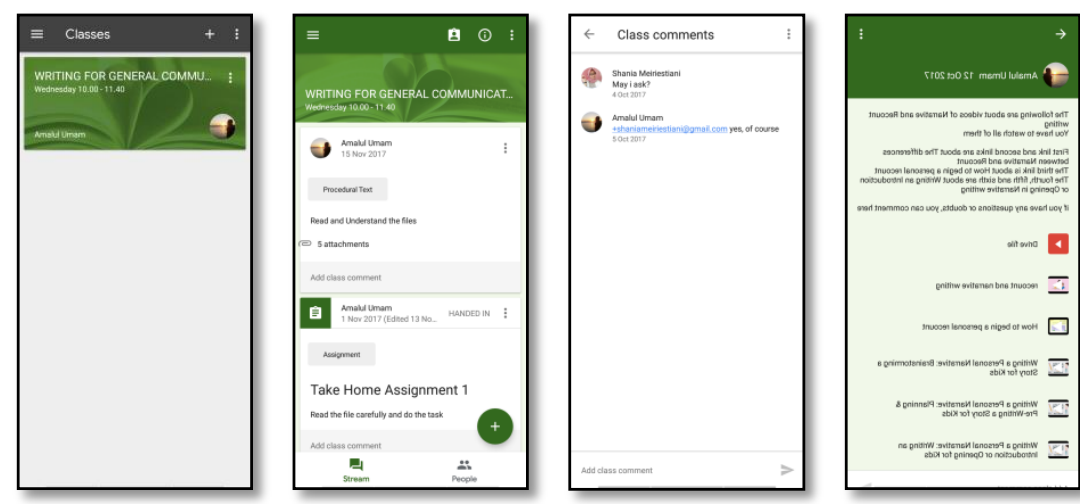

1.1.3 Tangkapan layar (screenshot) Google Classroom

d. Line

Line adalah aplikasi media sosial yang memungkinkan penggunanya melakukan panggilan gratis dan mengirim pesan gratis baik secara individu ataupun kelompok, dimanapun dan kapanpun (line.me).

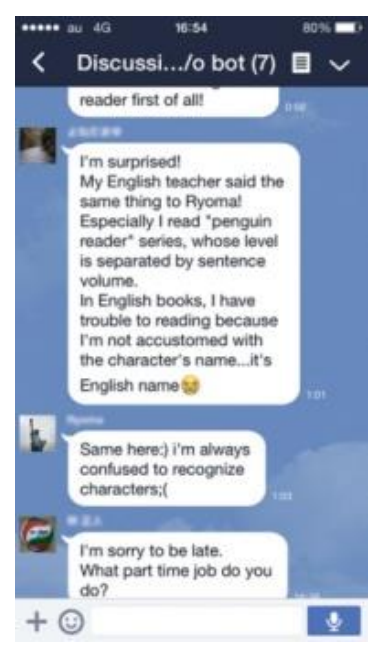

1.1.4 Tangkapan layar (screenshot) Line

Sumber: Mccarty \& Sato, 2017.

e. TED Talks

TED Talks adalah aplikasi yang menyuguhkan beragam video inspiratif yang dibawakan oleh orang-orang berpengaruh dari berbagai dunia (ted.com). 

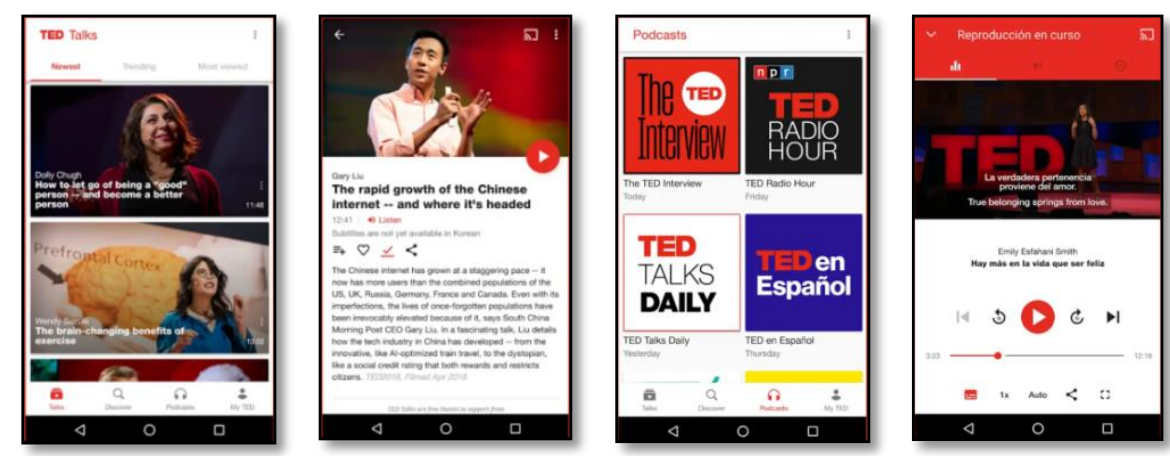

Sumber: ted.com

\subsubsection{Tangkapan layar (screenshot) TED Talks}

\section{Pihak-Pihak yang Membantu}

\section{Mengimplementasikan}

a. Dinas Pendidikan Daerah

Dinas Pendidikan Daerah berperan dalam menggalakan penggunakan teknologi untuk proses belajar mengajar dan mendukung pelatihan penggunaan teknologi bagi guru serta menyediakan tempat maupun fasilitas bagi pelatihan teknologi pada guru.

b. Sekolah

Sebagai instansi tempat proses belajar dan mengajar berlangsung, sekolah diharapkan dapat membantu merealisasikan gagasan ini dengan membuat peraturan baru mengenai pemakaian telepon seluler atau smratphone di dalam kelas, serta mengirim guru-gurunya secara bergantian untuk mengikuti pelatihan teknologi.

\section{c. Guru}

Guru sebagai orang pertama yang bertanggung jawab pada setiap kegiatan belajar mengajar yang terjadi di kelas memiliki tanggung jawab penuh dalam hasil yang ingin dicapai oleh siswanya. Motivasi dan strategi belajar yang peserta didik miliki sedikit banyaknya merupakan hasil dari exposure (paparan) yang diberikan oleh guru. Maka peran guru sangat penting dalam mewujudkan gagasan ini.

\section{Langkah-Langkah Strategis}

Dalam mewujudkan gagasan ini tentunya diperlukan langkah-langkah strategis agar gagasan ini dapat terealisasi dengan baik, yaitu:

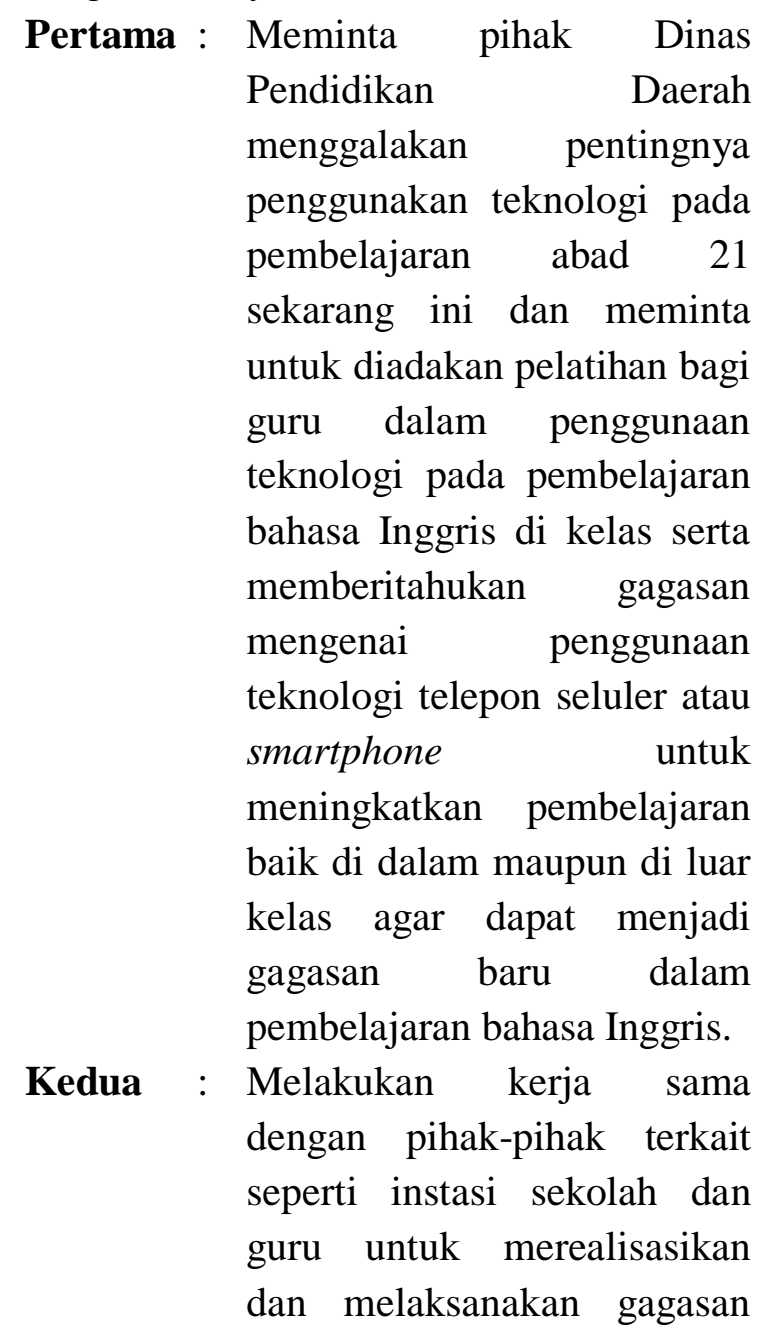


ini di dalam pembelajaran bahasa Inggris di kelas.

Ketiga : Kekurangan dan kelebihan dalam pendekatan ini agar

\section{KESIMPULAN}

Dalam proses pembelajarannya di kelas, pembelajaran bahasa Inggris masih menemui banyak masalah atau kendala terutama dengan menggunakan pendekatan dan metode belajar tradisional. Permasalahan yang banyak muncul adalah karena pendekatan dan metode yang digunakan sudah tidak lagi cocok digunakan di zaman sekarang ini terlebih lagi kepada generasi neo-milenial yang terbiasa hidup dengan teknologi dan media sosial sejak kecil (digital native). Oleh karenanya, dibutuhkan sebuah pendekatan baru yang dapat mengakomodasi kebutuhan belajar generasi neo-milenial dengan tujuan pendidikan itu sendiri.

Mobile Asisted Language Learning (MALL) sebuah pendekatan dengan menggunakan perangkat seluler untuk kegiatan belajar mengajar merupakan sebuah pendekatan yang sangat efektif penggunaannya dalam pembelajaran baik di dalam maupun di luar kelas, pendekatan ini juga merupakan pendekatan yang paling cocok digunakan di dunia teknologi sekarang ini terutama pada generasi neomilenal atau generasi yang dijuluki sebagai menjadi saran dan pembelajaran untuk metode dan pendekatan selanjutnya.

digital native. Selain itu dikarena perbedaan usia yang jauh antara guru dengan siswa terutama guru-guru senior, maka diperlukan adanya pelatihan pengenalan fitur-fitur dan media-media pada teknologi telepon seluler atau smartphone kepada guru. Harapannya dengan menggunakan metode dan pendekatan ini, guru akan lebih mudah untuk mengajarkan dan meningkatkan kemampuan bahasa Inggris pada siswa.

Penulis menyadari dalam merealisasikan metode dan pendekatan ini diperlukan kerja sama dengan semua pihak antara lain Dinas Pendidikan Daerah, sekolah, dan guru. Serta pihak-pihak lain yang juga memiliki kontribusi besar dalam pendekatan ini seperti orang tua siswa dan siswa sendiri. Dengan berhasilnya penerapan pendekatan ini dalam pembelajaran bahasa Inggris di dalam maupun di luar kelas, diharapkan pendekatan ini dapat meningkatkan kemampuan siswa dalam keterampilanketerampilan bahasa Inggris seperti listening, speaking, writing, reading, grammar, vocabulary dan pronunciation. 


\section{DAFTAR PUSTAKA}

Azhar, K. A., \& Iqbal, N. (2018). Effectiveness of Google Classroom: Teachers' Perceptions. Prizren Social Science Journal. Vol. 2. Issue 2.

Boholano, H. (2017). Smart Social Networking: 21st Century Teaching and Learning Skilss. Research in Pedagogy. Vol. 7, Issue 1.

Chrome Google . Read Aloud: A Text to Speech Voice Reader. Diakses 3 Januari 2019. https://chrome.google.com/webstore/ detail/read-aloud-a-text-tospee/hdhina didafjejdhmfkjgnolgimiaplp?hl=en.

Dehghan, F., Rezvani, R., \& Fazeli, S. A. (2018). Social Networks and Their Effectiveness in Learning Foreign Language Vocabulary: A Comparative Study Using Whatsapp. CALL-EJ. No. 2.

Edmodo. About Edmodo. Diakses 1 Januari 2019. https://www.edmodo.com.

Kominfo. (2014). Riset Kominfo dan UNICEF Mengenai Perilaku Anak dan Remaja Dalam Menggunakan Internet. Siaran Pers No.17/PIH/KOMINFO/2/2014.

Diakses 29 Desember 2018. https://kominfo. go.id/index.php/content/detail/3834/ Siaran+Pers+No.+17-PIHKOMINFO-2-

2014+tentang+Riset+Kominfo+dan+ UNICEF+Mengenai+Perilaku+Anak + dan+
Remaja+Dalam+Menggunakan+Inter net+/0/siaran_pers

Lindaman, D., \& Nolan, D. (2015). Mobile-Assisted Language Learning: Application Development Projects within Reach For Language Teachers. The International Association for Language Learning Technology (IALLT) Journal. Vol. 45, No. 1.

Line. About Line. Diakses 1 Januari 2019. https://line.me/en/.

Mccarty, S., \& Sato, T. (2017). Implementing Mobile Language Learning Technologies in Japan. SpringerBriefs in Education. ISBN 978-981-10-2449-8.

Miangah, T. M., \& Nezarat, A. (2012). Mobile-Assisted Language Learning. International Journal of Distributed and Parallel Systems (IJDPS). Vol.3, No.1.

Mohr, K. A. J., \& Mohr, E. S. (2017). Understanding Generation Z Students to Promote a Contemporary Learning Environment. Journal of Empowering Teaching Excellence. Vol. 1. Issue 1.

Motteram, G. (2013). Innovations in Learning Technologies for English Language Teaching. British Council 2013/C607. ISBN 978-0-86355-7132.

Pim, C. (2013). Emerging Technologies, Emerging Minds: Digital Innovations within the Primary Sector. British 
Council 2013/C607. ISBN 978-086355-713-2.

Stanley, G. (2013). Integrating Technology into Secondary English Language Teaching. British Council 2013/C607. ISBN 978-0-86355-7132.

Taj, I. H., Sulan, N. B., Sipra, M. A., \& Ahmad, W. (2016). Impact of Mobile Assisted Language Learning (MALL) on Efl: A Meta-Analysis. Advances in Language and Literacy Studies. Vol. 7, No. 2.

Takeda, I. (2016). Report: Project-Based Learning with 21 st Century Skills for the Japanese Language Classroom.
Journal of Integrated Creative Studies.

Ted. History of TED. Diakses 1 Januari 2019.

https://www.ted.com/about/ourorganization/how-ted-works.

Yaman, I., \& Ekmekçi, E. (2016). A Shift From Call to Mall?. Practicipatory Educational Research. Issue 4.

Yudhiantara, R. A., \& Saehu, A. (2017). Mobile-Assisted Language Learning (MALL) in Indonesian Islamic Higher Education. IJELTAL (Indonesian Journal of English Language Teaching and Applied Linguistics). Vol. 2, No. 1. 